\title{
Chapter 14 \\ Biodiversity Conservation through Various Citizen Activities in a Flood Control Basin
}

\author{
Jun Nishihiro, Shohei Koike, and Atsushi Ono
}

\begin{abstract}
Flood control basins (FCBs) are artificially constructed facilities with the potential to conserve the biodiversity of floodplain ecosystems. However, the intensity of disturbance in FCBs is generally lower than that in natural floodplains; thus, habitats for plants with disturbance-dependent life histories and for animals that use temporary waters or mudflats can be lost in the years following FCB construction. Here, the Asahata FCB in Shizuoka city, Japan, was studied as an example, where the species diversity of wetland plants has been conserved as a result of diverse activities. Although most activities had objectives other than biodiversity conservation, they contributed to conserving plant diversity and providing habitats for endangered plants. The FCB is a green infrastructure that not only enables flood control but also supports activities for various purposes. Additionally, its proper use contributes to biodiversity conservation.
\end{abstract}

Keywords Biodiversity · Citizen participation - Education · Endangered plants · Welfare

\subsection{Introduction: Floodplain and Flood Control Basin}

\subsubsection{Floodplain}

In lowland plains, rivers that have not been artificially modified meander and change the channel morphology during flooding events (Bridge 2003). Such dynamics of

J. Nishihiro $(\bowtie)$

National Institute for Environmental Studies, Ibaraki, Japan

e-mail: nishihiro.jun@nies.go.jp

S. Koike

Toho University, Tokyo, Japan

A. Ono

Showa Sekkei Co., Ltd., Osaka, Japan

(C) The Author(s) 2022

F. Nakamura (ed.), Green Infrastructure and Climate Change Adaptation,

Ecological Research Monographs, https://doi.org/10.1007/978-981-16-6791-6_14 
the river channel result in a floodplain. Because the intensity of flood disturbances varies among locations within a floodplain, a mosaiclike ecosystem composed of heterogeneous elements is formed, providing a habitat for diverse flora and fauna (Junk et al. 1989; Tockner et al. 1998; Ward et al. 1999; Robinson et al. 2002; Tockner and Stanford 2002).

In recent years, the area and biodiversity of floodplains have decreased worldwide (Tockner and Stanford 2002; Ishiyama et al. 2017). In Japan, which is mostly mountainous, floodplain areas have been targeted for land use development. Many major Japanese cities are located on alluvial plains at low elevations, which constituted the seabed during the Holocene glacial retreat. Furthermore, these alluvial plains are suitable for modern rice cultivation; therefore, large areas of the plain have been converted into modernized agricultural land. In addition to land conversion, flow control by dams in the upper reaches of rivers causes biodiversity loss in floodplains. The reduction in flood disturbance in turn reduces the habitat areas of plants with life history characteristics that depend on disturbance and of animals that exploit temporary water (Nakamura et al. 2006).

\subsubsection{Potential of Flood Control Basins}

To conserve floodplain biodiversity, it is important to preserve areas affected by flood disturbances. In flood control basins (FCBs), the biodiversity of floodplain ecosystems can be conserved, even in Japan, where the population density is high and lowland plains are often subject to development. An FCB is an artificially constructed facility intended to reduce river flow due to rainfall occurring during peak floods (Fig. 14.1). Although FCBs are designed to reduce flood risk, they have similar hydrological characteristics to natural floodplains, i.e., they are temporarily inundated only during floods. Therefore, they can provide habitats for species with life history characteristics that depend on disturbances caused by floods.

There are 143 FCBs in Japan, with a total area of 15,104 ha (Suwa and Nishihiro 2020). However, not all of these factors may contribute to the conservation of floodplain ecosystems. There are many differences between FCBs and natural floodplains, a major difference being the intensity of the disturbance. In many FCBs, only water that exceeds the overflow dike, which is built as a relatively low part of the dike between the river channel and FCB, can enter the basin. Thus, there is insufficient energy to disturb vegetation and soil. In some areas of natural floodplains, the flood energy is sufficiently high to remove preexisting vegetation; however, identification of such areas in FCBs is difficult. In stable wetland environments, the biomass of aboveground vegetation commonly increases over time, and a transition to woodland occurs through vegetation succession (Salo et al. 1986). This change can be rapid because the nutrient input is high in FCBs as a consequence of sedimentation. Thus, habitats for plants with disturbance-dependent life histories and for animals that use temporary waters or mudflats can be lost within only a few years of FCB construction. 
Fig. 14.1 The functioning Asahata flood control basin. (a) Floodwaters overflowing part of the levee (overflow dike), entering the FCB. (b) FCB during floods. (c) FCB under normal circumstances
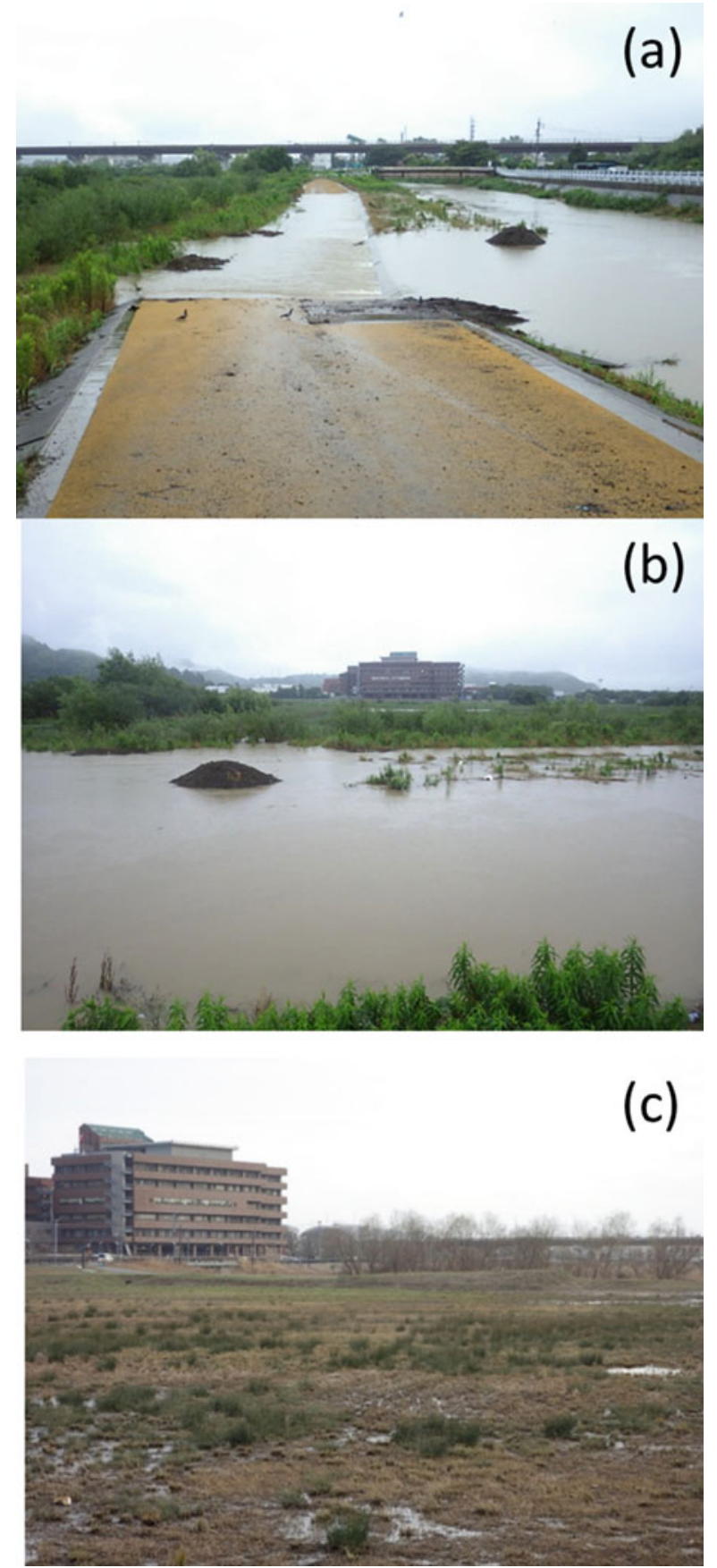


\subsubsection{Utilization of Land in a Flood Control Basin}

FCB functions to reduce flood risk but can also be used for sports, recreational activities, environmental education, and paddy cultivation; additionally, their vegetation can be used as a source of materials for traditional thatched roofs. Appropriate planning of these activities is expected to contribute to biodiversity conservation. If so, disturbances caused by floods can be replaced by disturbances caused by human activities.

However, not all disturbances have a positive effect on biodiversity. Local biodiversity is high only under moderate disturbances ("intermediate disturbance hypothesis," Connell 1978). Excessive anthropogenic disturbances can lead to a decline in biodiversity. Moreover, the intermediate hypothesis is that species diversity within a spatial unit can be considered a homogeneous environment $(\alpha-$ diversity). Higher $\beta$-diversity, defined as a greater heterogeneity between different locations, is another characteristic of floodplain biodiversity. The effects of disturbance on FCB biodiversity should be evaluated in terms of both $\alpha$ - and $\beta$-diversity.

The Asahata FCB in Shizuoka city, Japan, was constructed to control floods in the Tomoe River. Many groups and individuals, including nature conservation groups, private companies, special schools for students with disabilities, and hospitals, participate in activities in the FCB (Nishihiro 2018). We studied the effects of these activities on the vegetation in the FCB. First, we provide background information and discuss the research results regarding the relationship between these activities and vegetation.

\subsection{Asahata Flood Control Basin}

\subsubsection{Geomorphological Features and Changes in Land Use}

The Tomoe River is $17.98 \mathrm{~km}$ long, and its watershed covers an area of $104.8 \mathrm{~km}^{2}$. The watershed comprises approximately $7.6 \%$ of the total area of Shizuoka city but contains $47 \%$ of the total population (approximately 340,000 people). The lower parts of the river basin are urbanized areas.

The Tomoe River Basin was a bay during the Holocene glacial retreat, and most of the basin was flat. The FCB was built at the inflection point of the riverbed slope, where the river leaves the mountains and reaches the low land (Fig. 14.2). Until about 50 years ago, many swamps were scattered in this area (Yasumoto 1979). The paddy fields of this swampy area were inundated throughout the seasons, and rice productivity was low. Traditional fisheries for eels, loaches, shrimp, and carp were established in the Edo era (the late 1800s; Yasumoto 1979). From 1959 to 1973, a project was carried out to improve agricultural productivity, including wetland drainage and paddy field enlargement. 

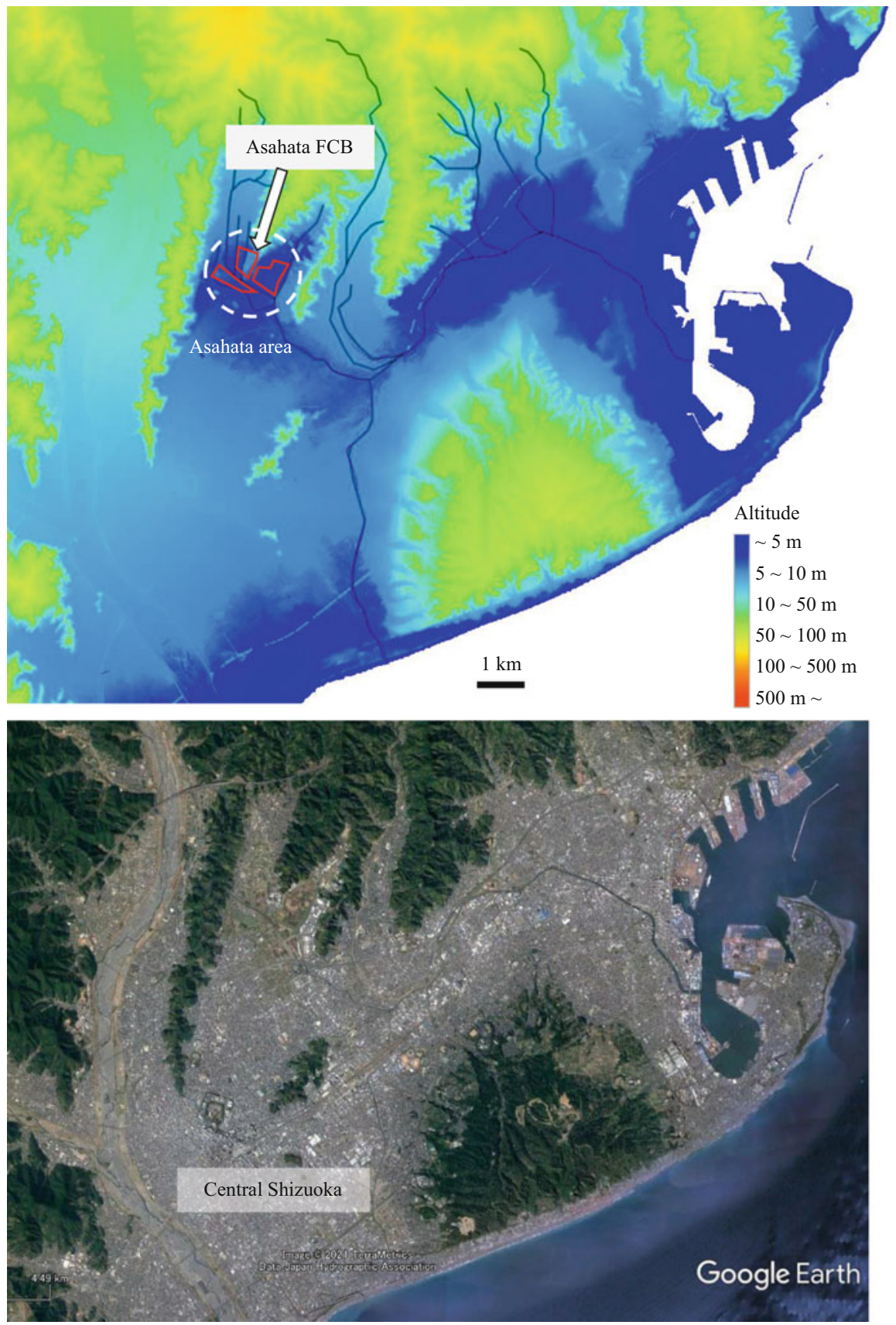

Fig. 14.2 Location of the Tomoe River (black line of upper panel) and location of the Asahata flood control basin. The lower panel shows Google Earth Image (March 2021 image) 
Although this project greatly increased the rice productivity of agricultural land, the discharge capacity of the Tomoe River itself was low, and the risk of flooding in the watershed remained high. On July 7 and 8, 1974, Typhoon \#8 caused heavy rain, leading to 41 deaths, the destruction of 32 houses, and above- and underfloor inundation of 11,981 and 14,143 houses, respectively. Because of this damage, a hydraulic control plan was established for the Tomoe River Basin in 1978, which included the construction of the Asahata FCB.

\subsubsection{Activities in the Asahata Flood Control Basin}

In the early 2000s, during the construction of the FCB, various plants, including the endangered disturbance-dependent species Monochoria korsakowii, grew extensively in the FCB due to disturbances caused by the construction work. The Nature Restoration Council, a local council for ecosystem management established under the Act to Promote Nature Restoration, was launched in 2003. The council initially focused on activities aimed at conserving biodiversity, of which the primary focus was the maintenance of the habitat of endangered plants. However, the range of activities was limited, and the number of participants did not increase over time.

In 2014, several new groups started to use the Asahata FCB, including people with disabilities attending special schools located near the FCB and staff from two local hospitals. New activities were encouraged by executives of the prefectural department and hospitals. Paddy fields were created to provide opportunities of job training to students with disabilities. With the provision of activities aimed mainly at welfare and education, local private companies and nongovernmental organizations also participated; thus, the total number of organizations participating in the Nature Restoration Council increased rapidly (Fig. 14.3). The number of participants in the

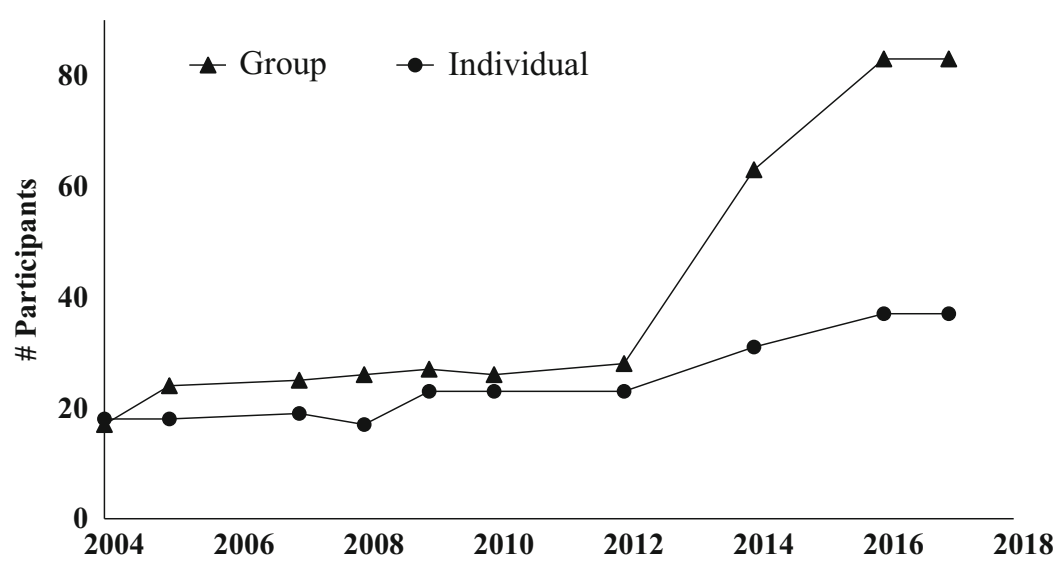

Fig. 14.3 Number of group and private participants of the Nature Restoration Council, Asahata flood control basin 
council was about four times larger in the period when groups whose main purposes were welfare and education were included in the council than that in the period when it was composed of groups whose main purpose was biodiversity conservation.

\subsection{Effect of Activities on Plant Diversity}

\subsubsection{Activities}

We identified nine types of activities that caused anthropogenic disturbances in the Asahata FCB (Table 14.1, Fig. 14.4). Only one activity, management of $M$. korsakowii habitat, had biodiversity conservation as its primary purpose (Table 14.1). Other activities included the management of paddy fields for students with disabilities, as mentioned above, as well as conducting classes for students with disabilities; focusing on the study of soil seed banks; transplanting plants to other parts of the retarding basin; excavating a pond to increase the storage capacity of the FCB, collecting Carex dispalata and Zizania latifolia to make traditional grass hats and grass mats, respectively; controlled burning to prevent vegetation succession; and mowing to make firebreaks to facilitate controlled burning.

Some activities had biodiversity-related objectives. For example, an educational program for studying soil seed banks was conducted as follows:

1. The students attended a lecture on plant diversity and soil seed banks.

2. The students collected soil samples from the FCB and spread them in containers placed in the school garden.

3. The plants that emerged from the soil samples were checked and identified throughout the year, and the flora of the seed bank was recorded.

4. After the experiment, the soil samples containing high-density seed banks (newly dispersed seeds were added from the plants that emerged in the soil) were moved and spread in the FCB.

The main objective of this program was to educate students, but the content of the training program was closely related to the conservation of plant diversity. In another case, while the main purpose of excavating the pond was to increase the capacity for water retarding, biodiversity was also considered. In contrast, the activities involving collection of plant materials did not consider biodiversity conservation as an objective. Overall, there was a high diversity among activity objects.

\subsubsection{Vegetation}

The activities listed in Table 14.1 can have different impacts on the ecosystems of the FCB. Of the nine activities, four involved only mowing aboveground vegetation, 


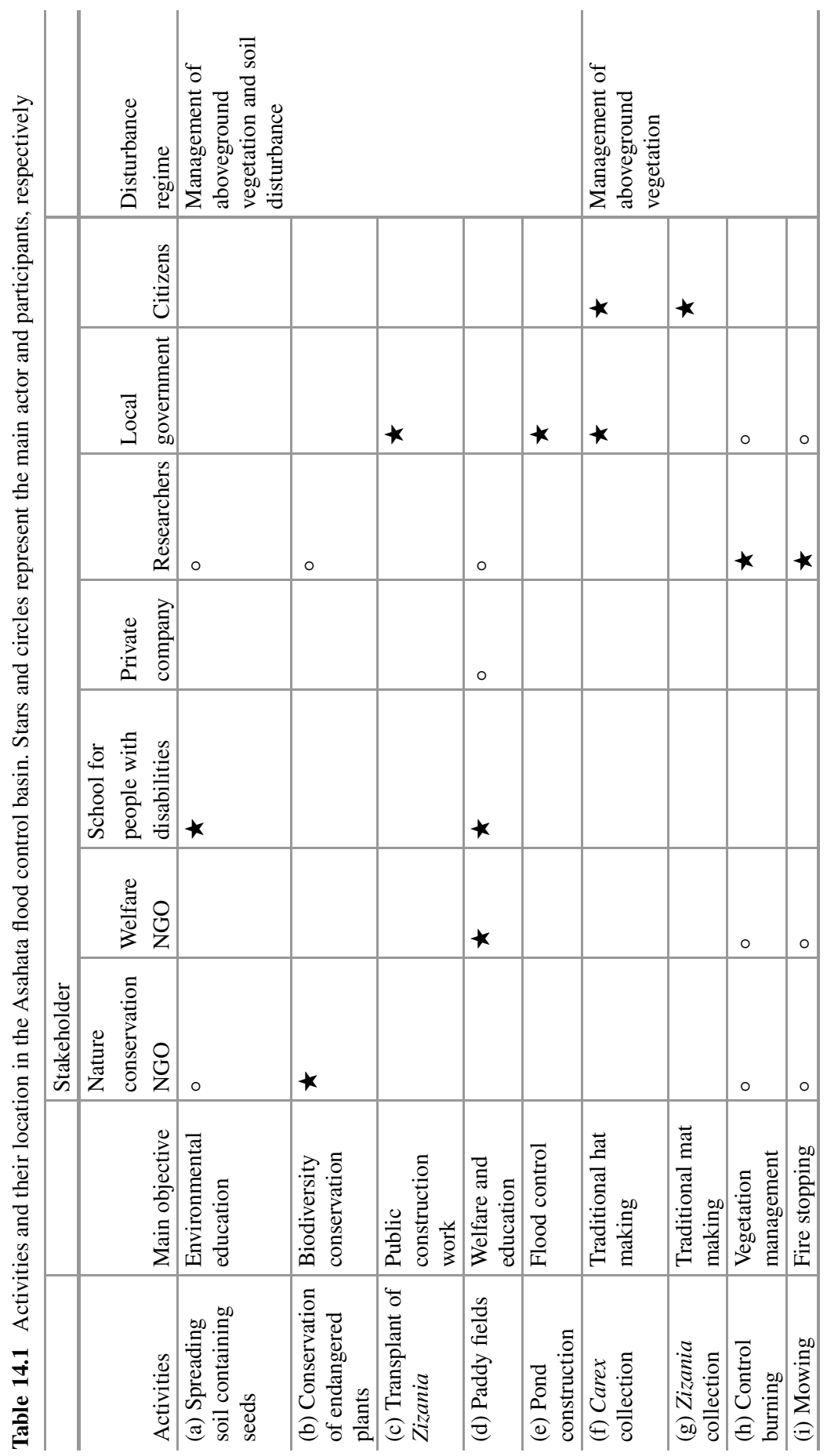



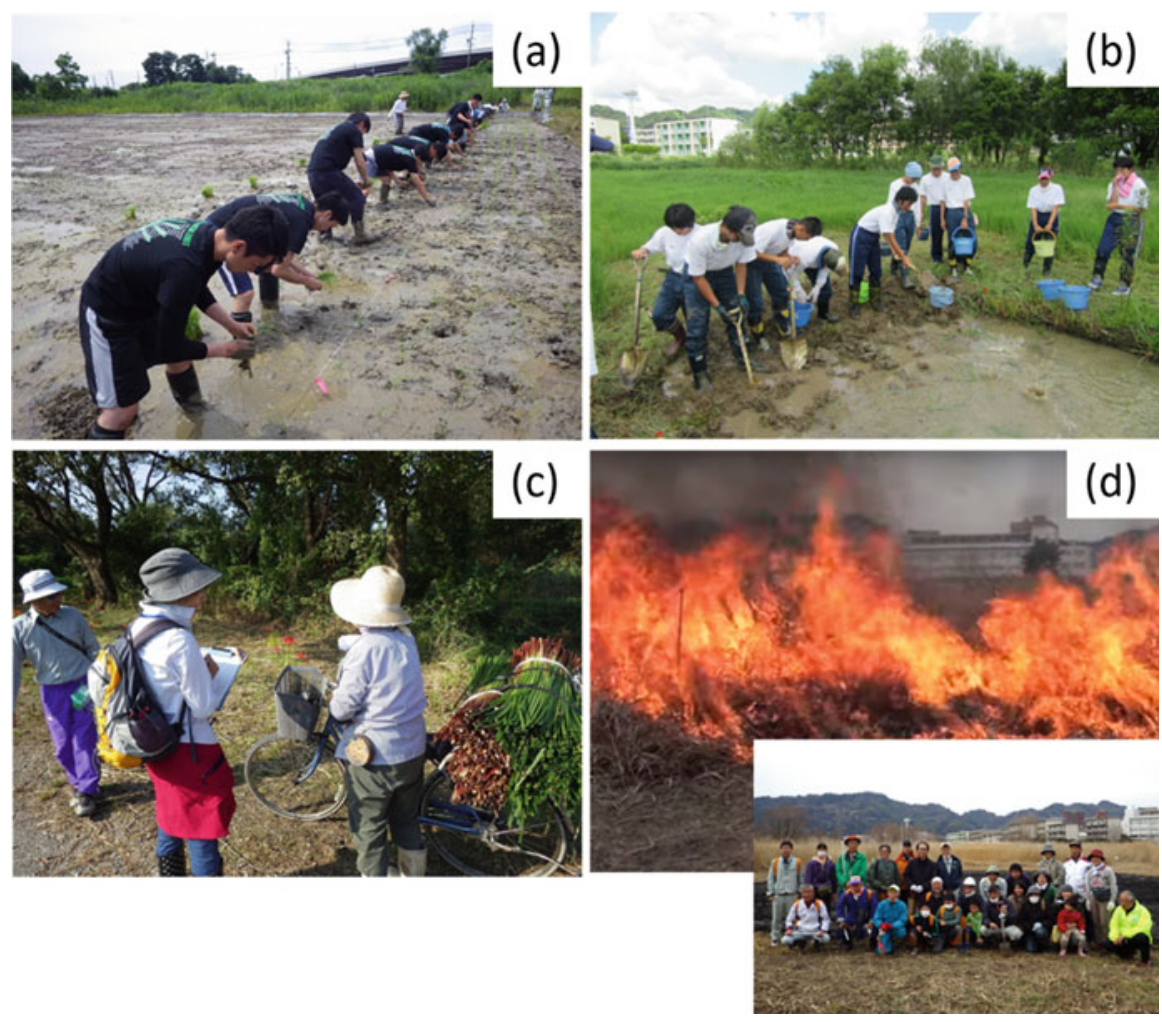

Fig. 14.4 Various activities in Asahata flood control basin. (a) Rice planting in a paddy field by students from a special-needs school. (b) Soil with high density of seed banks is being returned to the FCB by students from a special-needs school. (c) Collection of Zizania to make traditional rush mat. (d) Winter burning with the participation of many citizens

while five included both mowing and disturbing the soil. We conducted a vegetation survey to assess the impact of these activities on vegetation in the Asahata FCB. A $10 \mathrm{~m}^{2}$ plot was set up in each area where the activities listed in Table 14.1 were conducted, and all vascular plants were recorded. A similar survey was conducted in a control plot in an area adjacent to each activity site. The control plots were similar in terms of altitude and soil origin.

In total, 97 plant species were recorded, of which 77 were native species (including 53 wetlands or aquatic species). Of these 97 species, 58 (60\%) were observed only in plots that underwent activities (Fig. 14.5). In addition, five species on the Japanese Red List were recorded, all of which were found only in plots with activities. There were more species in the activity than in the control plots in areas where the soil was disturbed, with one exception (Fig. 14.6). Although the number of species was small in this exceptional plot, submerged plants were found only 

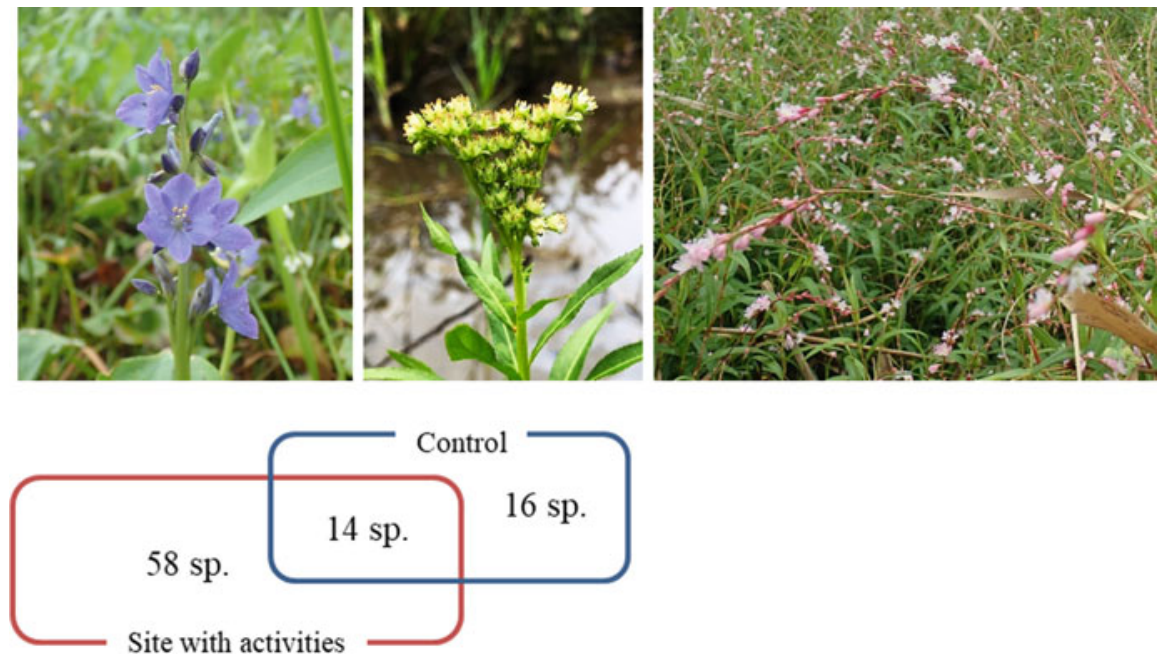

Fig. 14.5 Endangered species observed in the sites with activities: Monochoria korsakowii, Penthorum chinense, and Persicaria conspicua (from left to right). The numbers of species (sp.) in sites with activities and/or without activities (control) are also shown

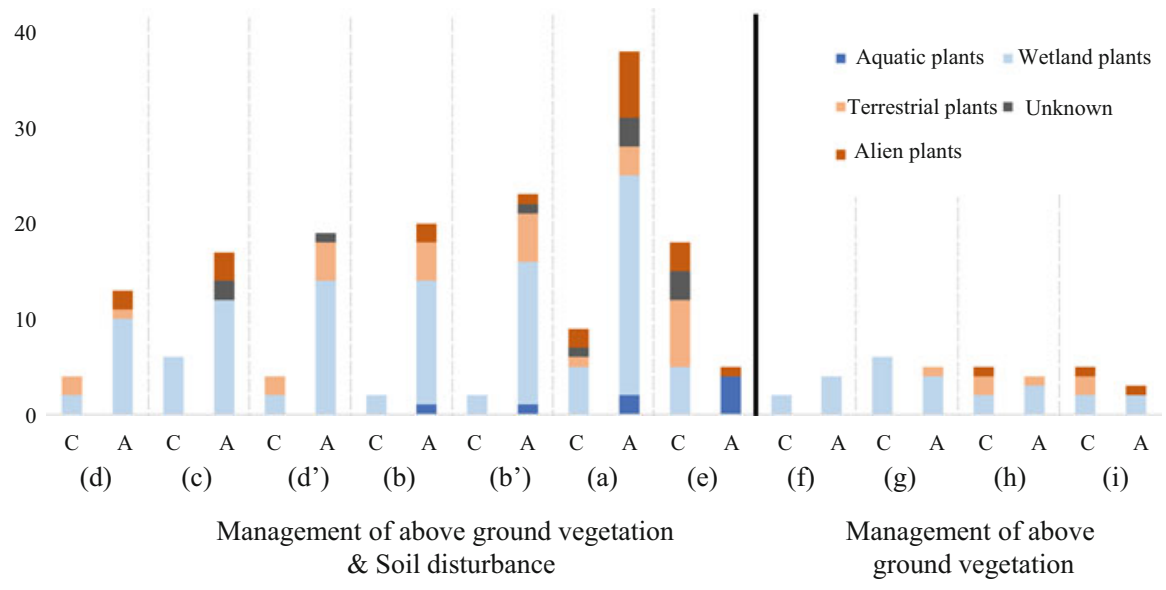

Fig. 14.6 Number of species observed in each site with activity (A) and control (C). The activities (a) to (i) correspond with these in Table 14.1. (b') and (d') represent the ridge of the paddy (b) and (d), respectively

in the plot. In other words, highly specific vegetation, which contributes to the $\beta$ diversity of flora in Asahata FCB, was established in this plot.

Activities in the Asahata FCB contributed to the maintenance of plant diversity. Most of the observed plants were wetlands and aquatic plants, suggesting that activities in the Asahata FCB facilitated the conservation of floodplain vegetation. Anthropogenic disturbances due to activity in the FCB might partly replace natural 
disturbances, although it will be necessary to compare the vegetation of FCB to that of a natural floodplain to confirm this hypothesis.

In many cases, the number of alien plants was also higher in the activity plots than that in the control plots, suggesting that disturbance can increase the opportunity for the invasion of many plants. Controlling alien species can be an issue in the management of biodiversity conservation.

\subsection{Generality of the Results}

This study examined activities in the Asahata FCB from the viewpoint of biodiversity conservation. However, these results cannot be applied to all FCBs. The floodplain-like vegetation observed here is thought to have been derived from the soil seed banks of plants that had grown in paddy fields and swamps before the FCB was built. The topsoil is removed in most FCBs to maintain the capacity for retarding floodwater. However, in the construction of the Asahata FCB, the topsoil from the paddy fields was first secured in another location and then returned to the surface of the FCB after construction. This was thought to have enabled the establishment of vegetation with a high species diversity. The use of topsoil is particularly important for the conservation of plant diversity in FCBs.

Our study showed that the utilization of wetlands usually increases $\alpha$-diversity. However, not all activities in FCBs facilitate conservation, and some might significantly reduce biodiversity. For instance, under conditions of high invasion pressure from invasive alien species, disturbance can lead to a decrease in biodiversity. To prevent such situations, it is important to assess their impact before implementing activities. We consider that the Asahata FCB is being used appropriately, at least for the moment, owing to the consensus built among various stakeholders, including ecology experts.

\subsection{Activity Redundancy and Conservation Sustainability}

A shortage of participants may lead to discontinuation of the activities in the future, namely, for the "Use of Zizania" and "Use of Carex" activities listed in Table 14.1. In addition, the nature conservation group considers the aging of its members as problematic. Societal changes can make it difficult to continue an activity, the scale of which may have to be reduced. If an activity cannot be continued, the environment that depends on it will disappear, thus decreasing the biodiversity of the FCB. To maintain biodiversity under such uncertain circumstances, "activity redundancy," which refers to a variety of actors playing a similar role, is thought to be an important factor in long-term natural resource management. It will be important to allow activities with various purposes, not limited to biodiversity conservation, and to scientifically monitor the effects of these activities. It will also be important to have 
a mechanism to facilitate communication among participating groups and to help each other when necessary.

Acknowledgments We sincerely thank Ms. Kuriyama (Shizuoka city) for her cooperation. This study was partly supported by the Environment Research and Technology Development Fund JPMEERF20202001 of the ERCA of Japan.

\section{References}

Bridge JS (2003) Rivers and floodplains: forms, processes, and sedimentary record. Blackwell publishing, Oxford

Connell JH (1978) Diversity in tropical rain forests and coral reefs. Science 4335:1302-1310

Ishiyama N, Nagayama S, Iwase H, Akasaka T, Nakamura F (2017) Restoration techniques for riverine aquatic connectivity: current trends and future challenges in Japan. Ecol Civ Eng 19:143-164. (in Japanese)

Junk W, Bayley PB, Sparks RE (1989) The flood pulse concept in river-floodplain systems. In Dodge DP (ed). Proceedings of the international large river symposium (LARS). Canadian special publication of fisheries and aquatic sciences 106, pp. 110-127

Nakamura K, Tockner K, Amano K (2006) River and wetland restoration: lessons from Japan. Bioscience 56:19-429

Nishihiro J (2018) Efforts to balance the usage and conservation of biodiversity in Asahata retarding basin, Shizuoka. National Parks 763:16-19. (in Japanese)

Robinson CT, Tockner K, Ward JV (2002) The fauna of dynamic riverine landscapes. Freshw Biol 47:661-677

Salo J, Kalliola R, Hakkinen I, Makinen Y, Niemela P, Puhakka M, Coley PD (1986) River dynamics and the diversity of Amazon lowland forests. Nature 322:254-258

Suwa Y, Nishihiro J (2020) Distribution and location characteristics of flood-control reservoir in Japan. Ecol Civ Eng 23:85-97. (in Japanese)

Tockner K, Stanford JA (2002) Riverine flood plains: present state and future trends. Environmental Conservation 29:308-330

Tockner K, Shiemer F, Ward JV (1998) Conservation by restoration: the management concept for a river-floodplain system on the Danube River in Austria. Aquatic Conservation: Mar Freshw Ecosyst 8:71-86

Ward JV, Tockner K, Schiemer F (1999) Biodiversity of floodplain river ecosystems: ecotones and connectivity. Regul Rivers: Res Manage 15:125-139

Yasumoto H (1979) History of Asahata. Shizuoka city office. (in Japanese)

Open Access This chapter is licensed under the terms of the Creative Commons Attribution 4.0 International License (http://creativecommons.org/licenses/by/4.0/), which permits use, sharing, adaptation, distribution and reproduction in any medium or format, as long as you give appropriate credit to the original author(s) and the source, provide a link to the Creative Commons license and indicate if changes were made.

The images or other third party material in this chapter are included in the chapter's Creative Commons license, unless indicated otherwise in a credit line to the material. If material is not included in the chapter's Creative Commons license and your intended use is not permitted by statutory regulation or exceeds the permitted use, you will need to obtain permission directly from the copyright holder.

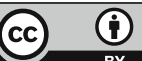

